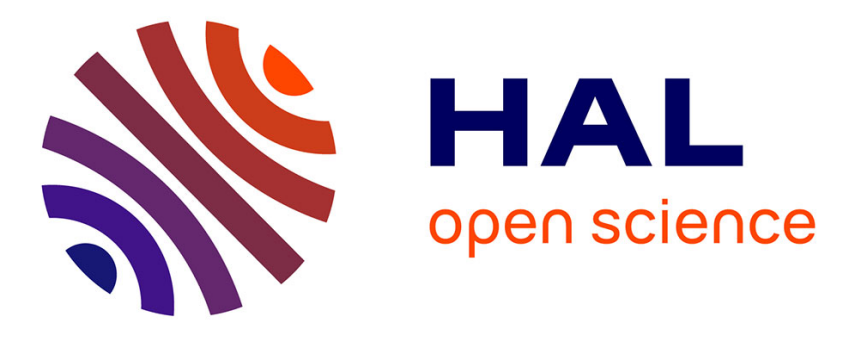

\title{
Nucleation and growth during a fluorogenic precipitation in a micro-flow mapped by fluorescence lifetime microscopy
}

Vu Long Tran, Valérie Génot, Jean-Frédéric Audibert, Yury Prokazov, Evgeny Turbin, Werner Zuschratter, Hyeong-Ju Kim, Jaehun Jung, Soo Young Park, Robert B. Pansu

\section{To cite this version:}

Vu Long Tran, Valérie Génot, Jean-Frédéric Audibert, Yury Prokazov, Evgeny Turbin, et al.. Nucleation and growth during a fluorogenic precipitation in a micro-flow mapped by fluorescence lifetime microscopy. New Journal of Chemistry, 2016, 40 (5), pp.4601 - 4605. 10.1039/c5nj03400k . hal01390265

\section{HAL Id: hal-01390265 \\ https://hal.science/hal-01390265}

Submitted on 4 Nov 2016

HAL is a multi-disciplinary open access archive for the deposit and dissemination of scientific research documents, whether they are published or not. The documents may come from teaching and research institutions in France or abroad, or from public or private research centers.
L'archive ouverte pluridisciplinaire $\mathbf{H A L}$, est destinée au dépôt et à la diffusion de documents scientifiques de niveau recherche, publiés ou non, émanant des établissements d'enseignement et de recherche français ou étrangers, des laboratoires publics ou privés. 


\title{
ARTICLE
}

Received 00th January 20xx, Accepted 00th January 20xx

DOI: $10.1039 / \times 0 \times x 00000 x$

www.rsc.org/

\section{Nucleation and growth during a fluorogenic precipitation in a micro flow mapped by fluorescence lifetime microscopy}

\author{
Vu Long Tran, Valérie Génot, Jean-Frédéric Audibert, \\ Yury Prokazov, ${ }^{ \pm}$Evgeny Turbin, ${ }^{ \pm}$Werner Zuschratter, ${ }^{ \pm}$ \\ Hyeong-Ju Kim, Jaehun Jung, ${ }^{\circ}$ Soo Young Park ${ }^{\circ}$ and Robert B. Pansu*
}

We have observed the precipitation of a fluorescent dye in a microfluidic 3D hydrodynamic mixing set up. In addition to the short fluorescence lifetime of DBDCS molecule and to the long lifetime of their crystal, nuclei with an intermediate lifetime are observed. We show that the precipitation is slowed down by the presence of a viscous skin at the interface between water and THF. From the analysis of the decays, we map the concentration of the three species over half a million pixels and show that nucleation and growth occur all along the device by a slow diffusion of the water into the THF inner flow.

\section{Introduction}

Precipitation has been used and investigated to produce solid materials for chemicals, foods and pharmaceutical industry for centuries. However, the demand for high quality nanomaterials nowadays makes it even more essential as a research topic. ${ }^{1,2,3,4}$ The recent emergence of microfluidic technology has enabled the precise fabrication of a wide variety of inorganic, organic and biological particles with narrow size distribution through precipitation..$^{5,6,7}$ At the same time, the mechanism of crystallisation: nucleation and growth ${ }^{8}$ is challenged by other models such as the presence of Pre Nucleation Clusters. ${ }^{9}$ This disordered aggregated state has been simulated, ${ }^{10}$ observed, ${ }^{11}$ and sometime are stable. ${ }^{12}$ The combination of microfluidics with imaging has also offered a new tool for observing the precipitation at both spatial and temporal micro-scales in order to understand the mechanisms behind it and to be able to control this highly stochastic process. Indeed, many efforts have been made to develop different sophisticated analytical methods for monitoring, visualizing, and finally studying the

\footnotetext{
Laboratoire PPSM ENS Cachan, CNRS, UMR8531 \& IFR d'Alembert IFR121

61, avenue du Président Wilson, 94235 Cachan cedex, France.

Fax: $+33(0) 147402454$

Tel: $+33(0) 147405338$

\pm Leibniz Institute for Neurobiology, Magdeburg, Germany

${ }^{\circ}$ Center for Supramolecular Optoelectronic Material

32dong 409ho, Seoul National University, \#599, Gwanak-ro, Gwanak-gu 155-744 Seoul, South Korea.

*Corresponding author, e-mail: robert.pansu@ppsm.ens-cachan.fr.

$+\quad$ Electronic Supplementary Information (ESI) available: Laser and microscopy setup, photophysical, morphological properties and fluorescence decays in THF
} solution of DBDCS, PCA algorithm, fitting curves. See DOI: 10.1039/x0xx00000x mechanisms and especially the kinetics of the precipitation from the early stages. For example, Van Driessche A. E. S. and co-workers have developed a method based on laser confocal microscopy combined with differential interference contrast microscopy to observe the crystallization of lysozyme and finally came up with a $2 \mathrm{D}$ nucleation rate. ${ }^{13}$ Transmission electron microscopy using liquid cells have been used by many authors to monitor the growth of metal nanoparticles from the solutions of different precursors. ${ }^{14}$ However, just a few methods have been integrated with microfluidic devices so far. Veesler S. and co-workers used a simple CCD camera to count the seed of crystals thanks to their special droplet-based microfluidic system. ${ }^{15,16}$ Sultana M. and Jensen K. F. applied Raman spectroscopy to determine in situ different polymorphic forms. ${ }^{11}$ Fluorescence microscopy has been applied by Schutze F. et al. to probe the formation of conjugated block copolymer nanoparticles when being introduced into an anti-solvent. ${ }^{17}$ In this article, we will introduce a platform incorporating fluorescence lifetime imaging microscopy (FLIM), which is one of the most sensitive and specific method, onto a simple microfluidic device to allow the in situ monitoring of the precipitation of an organic dye and the detection of the early steps of the nucleation and growth. We have been able to detect monomer, oligomers and solids in different positions in the flow. This platform has been developed with Rubrene as the model dye to visualize the precipitation. Rubrene has a longer

Fig. 1 DBDCS molecular structure. Formula: $\mathrm{C}_{32} \mathrm{H}_{32} \mathrm{~N}_{2} \mathrm{O}_{2} ; \mathrm{MW}=476.60$

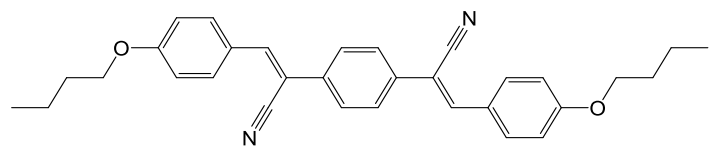




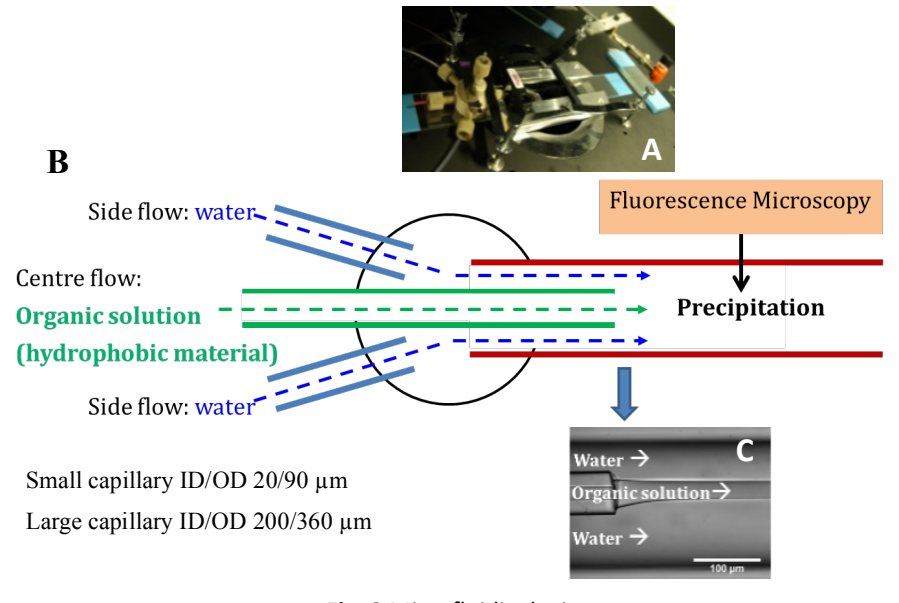

Fig. 2 Microfluidic device.

lifetime in solid state than in solution. The crystallisation process was observed and a control of the size by the flow ratio was shown. ${ }^{18}$ However, the device was made up of PDMS, which is incompatible with organic solvents and limits its usage time. Therefore, in this study, we will introduce a glass tubing microfluidic that is altogether cheap, versatile and compatible with organic solvents. ${ }^{19}$ Furthermore, we have chosen DBDCS (Fig. 1) as a model molecule for the detection of the early steps of the nucleation. Indeed this molecule exhibits an aggregation induced emission enhancement (AIEE), namely the molecules are non-fluorescent and the nuclei should appear as bright objects on a dark background. This molecule has been recently developed by Park S. Y. and co-workers and was known to have remarkable longer lifetime in solid states. ${ }^{20}$ From the analysis of the fluorescence decay for each pixel we have been able to distinguish the fluorescence of single molecules, big aggregates or nuclei namely intermediate species observed only in the very early stages of the micro-precipitation.

\section{Experimental}

\subsection{Chemicals}

DBDCS was chosen as a model dye since it emits fluorescence with a yield of 0.62 in the solid states compare to less than $3 e-3$ in the solution. The synthesis, characterization and proposed photophysics of DBDCS might be found extensively elsewhere. ${ }^{20-22}$ A table of the properties of DBDCS is provided in S2-ESI. Before studying its precipitation in the microfluidic device, we have recorded the fluorescence decays of DBDCS solutions in THF with increasing concentrations. A component with a longer lifetime than that of monomer (60 ps, instrumental response) is observed that indicates the formation of dimers and/or higher oligomers in the concentrated solutions (data are shown in S3-ESI).

\subsection{Microfluidic}

The microfluidic device was fabricated by simple components as shown in Fig. 2. The device includes a PEEK polymer manifold holding two silica capillaries (green and red colour on the schema) that are highly resistant to organic solvents and transparent to UV. The inner capillary goes through the manifold whereas the outer capillary is filled with water (blue) by two Teflon tubes connected to two other ports of the manifold (Fig. 2A-B). First, water was pumped through the two tubes into the large capillary. Then, organic solution (e.g. THF) of DBDCS was introduced. When the two solutions mix, the organic material in THF precipitates. Different from batch precipitation, in a micro capillary, no turbulence occurs, as laminar flow is predominant. Therefore, the only mechanisms of the mixing are the cross diffusion of two solvents and the molecular diffusion of the organic material. The modulation of the ratio of the outer and inner flow changes the inner flow diameter and the rate of inter-diffusion. This method, which is called 3D hydrodynamic focusing, was successfully applied to previous studies to synthesize nanoparticles with narrow size distribution. $^{23,24}$

\subsection{FLIM acquisition and analysis}

The precipitation indicated by a gradient of fluorescence of the dye was visualized by a fluorescence microscopy setup. The key element is a single photon counting photomultiplier able to localize the impact of the photon on the photocathode in space $(40 \mu \mathrm{m}$ resolution) and in time (60ps resolution) This FLIM detector is developed at Leibniz Institute for Neurobiology. A full fluorescence decay with four thousand channel points, can be collected for each pixel of the image. ${ }^{25}$ The analysis of a single multi-exponential decay has been already a difficult task. ${ }^{26}$ The fit of hundred thousand parallel decays would be extremely time-consuming. Hence, other approaches have to be developed. A commonly used method is the Phasor approach where a graphical representation of the result of the Fourier transform of the data gives an estimation whether a pixel is mono-, bi- or multi-exponential. ${ }^{27}$ However, in this study, a PCA approach was introduced. ${ }^{28}$ The details of the algorithm are provided in S4-ESI.

\section{Results and discussion}

\subsection{FLIM images of the precipitation}

We have screened different running conditions of the microfluidic device, the most promising FLIM images were collected at $0.1 \mathrm{mg} / \mathrm{ml}$ of DBDCS in THF and with the flow rate of the side flow (water) and the centre flow (THF solution of DBDCS) Qs/Qc $=10 / 0.5(\mu 1 / \mathrm{min})$. This condition made it possible to balance between a detectable intensity of the fluorescence signal and acceptable clogging rate to allow enough acquisition time. 


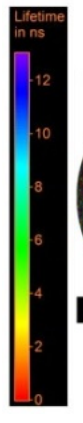

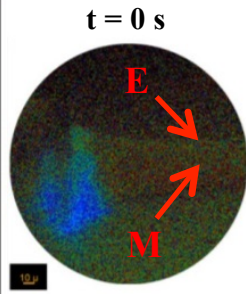

$\mathbf{d}=\mathbf{0} \mathbf{~ m m}$

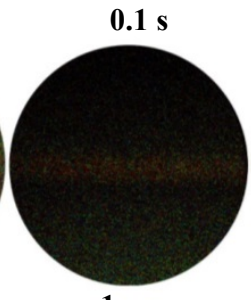

$1 \mathrm{~mm}$

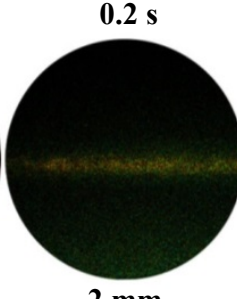

$2 \mathrm{~mm}$

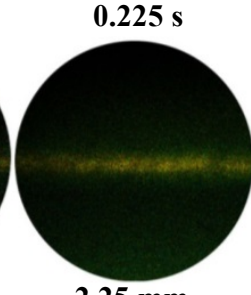

$2.25 \mathrm{~mm}$

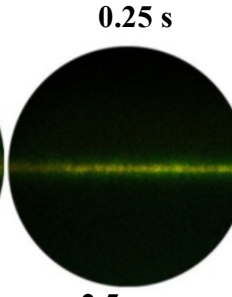

$2.5 \mathrm{~mm}$

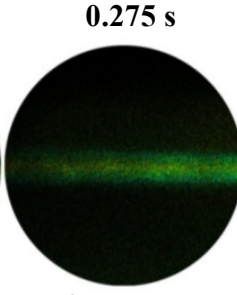

$2.75 \mathrm{~mm}$

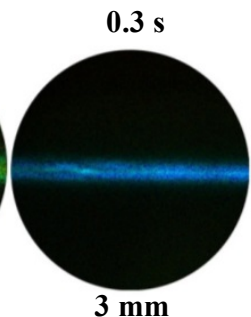

Fig. 3 FLIM images of the microprecipitation of DBDCS inside the microfluidic device; Qs $/ Q \mathrm{c}=10 / 0.5(\mu \mathrm{l} / \mathrm{min}), \mathrm{C}=0.21 \mathrm{E}-3 \mathrm{~mol} / \mathrm{L}$; inner flow diameter=30 $\mu \mathrm{m}$ The Colour of pixel codes for the average lifetime. The transit time at which precipitation starts (>100ms) is long compared to the inter-diffusion time of Water into THF (50ms)

Fig. 3 shows FLIM images from the tip of the capillary to the position $3 \mathrm{~mm}$ away from it. We have observed qualitatively different stages of the precipitation. The continuous change of lifetime from short (red) to long (blue) indicates the change of state from solution to solid along the capillary. Especially, the images at 2.5 and $2.75 \mathrm{~mm}$ confirmed that the solids started to appear at the edge of the central flow. The blue domain on the image at $\mathrm{t}=0 \mathrm{~s}$ is due to the presence of a precipitate at the tip of the inner tube, that is a prelude to the clogging of the device by the precipitate. In every image, the very short lifetime fluorescence of the monomers (red colour) and long lifetime fluorescence of the solids (blue colour) are present. Different questions arise here as 1) how many fluorescent species are present, 2) what are their decays and 3) where are they located.

\subsection{Detection of the intermediate state of the aggregates}

In order to address these questions, we have analysed the data by the Principle Component Analysis (PCA) to count and localize the different fluorescence decay type present in the images. The fluorescence decay curves from 18 regions of interest that correspond to the edge and the middle (red arrows on Fig. 3) of the central flow at different positions along the channel were collected and analysed. The results of PCA showed that $90 \%$ of the fluorescence (Fraction of varianceInsert of Fig. 4) could be described by only three components.

Fig. 4 The insert shows that three first components dominate describe more that $90 \%$ of the decays recorded in the images. These three components can be estimated from specific places in the device.

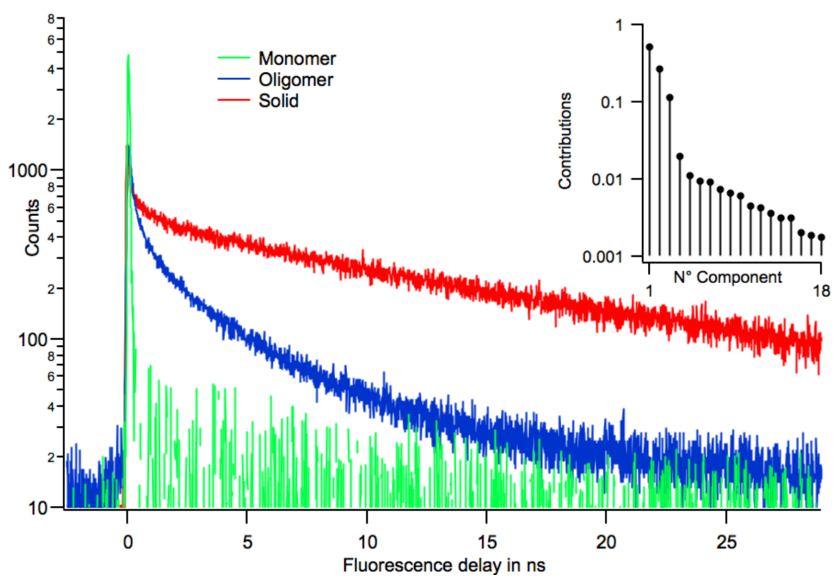

We assume that those components as fluorescence from solids, intermediates and monomers in solution. The signature decay for the solid was collected from the solid deposit observed at the tip of the inner capillary. The signature decay of the monomers was collected from the average of the fluorescence in the middle of the central flow at 0 and $1 \mathrm{~mm}$ where the precipitation was assumed not to have happened. The small oligomers have a lifetime in the nano-second range (Fig. S3). The decay of the intermediate species was constructed from the PCA components assuming the absence of fluorescence after $25 \mathrm{~ns}$ as describe in the S4-ESI.

\subsection{Localisation of the intermediates}

The contribution of the three components at each pixel can be easily calculated as a Euclidian scalar product as shown in the S4-ESI. The image at $3 \mathrm{~mm}$, that exhibits a highly multi exponential decay, was chosen to apply our localization technique.

The real image and reconstructed images of the three components are shown in Fig. 5. Fig. 5C confirms that monomers (green colour labelled) localize in the centre of the flow, while the solids (blue colour labelled) are at the edge of the flow. This is even better visualized by co-localized image (Fig. 5E) of the two components. The yellow colour in the middle of the flow indicates a superimposition of the two fluorescence signals. The oligomer and the crystal have the same localisation as shown by the violet colour of their colocalization image (Fig. 5F). The join presence of oligomers and crystal fluorescence show that the nucleation and growth processes are occurring simultaneously in this part of our microfluidic setup.

The results of the PCA analysis have been compared with those given by a multiexponential fit of the decays in some ROI. Biand tri-exponential model turned out to be insufficient to establish a precise fitting (data not shown). Hence, tetraexponential model was chosen (Eq. 1).

$$
y=y_{0}+A_{1} \exp \left(\frac{x}{\tau_{1}}\right)+A_{2} \exp \left(\frac{x}{\tau_{2}}\right)+A_{3} \exp \left(\frac{x}{\tau_{3}}\right)+A_{4} \exp \left(\frac{x}{\tau_{4}}\right)
$$




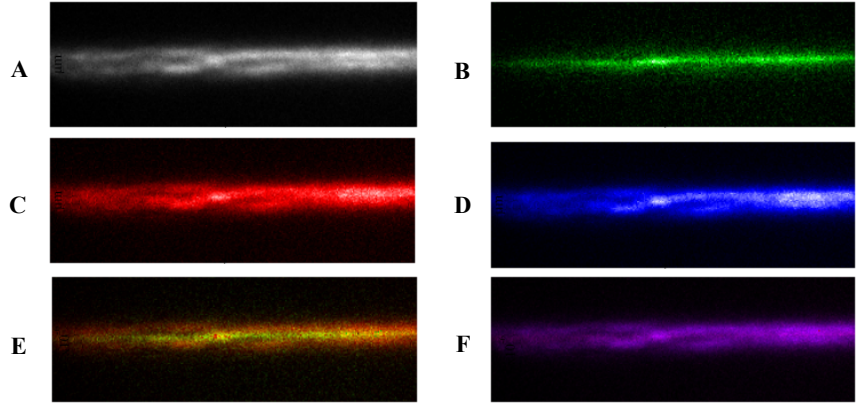

Fig. 5 Real and reconstructed (by PCA) fluorescence intensity at $3 \mathrm{~mm}$. A) real image; $B, C, D)$ reconstructed images of the fluorescence from monomers (green), oligomers (red) and crystals (blue) (the colours have no physical mean (n), $E$, $F$ ) co-localization of monomer-oligomer and oligomer-

Four components were assumed to contribute to the decays are 1) monomers with as short lifetime below the limit of the instrument, 60 ps 2) solid 1 and 3) solid 2 with lifetimes close to the data previous published $5.7 \mathrm{~ns}$ and $11.4 \mathrm{~ns}$ respectively (see "B-phase crystal" and "nanoparticles" in Table S2) and 4) intermediate species with a reasonable lifetime that give the best fit, 0.47 ns. The fitted curves and their corresponding weighted residuals are shown in Fig. S5. The pre-exponential coefficients of each lifetime component were shown in Table 1. The evolution of the precipitation with the residence time is clearly confirmed. First, from the centre of the point at $225 \mathrm{~ms}$ to the edge of the one at $300 \mathrm{~ms}$, the fluorescence of monomer decreases from $96.6 \%$ to $37.2 \%$ while that of the intermediates increases from 2.5 and $3.5 \%$ to 21.6 and $29.1 \%$. Second, the precipitation seems to really start from the edge before reaching the middle of the central flow. That is demonstrated by the fact that the percentages of the monomer at the edge of different positions are always lower than the percentages in the middle. On the contrary, the percentages of the intermediate and solid species at the edge of different positions are always higher than their percentages in the middle. Finally, the contribution in the fluorescence signal of the solid 1 is nearly negligible. Thus, solid 1 might be only the artefact of the background fluorescence or represented a very transient state. This result again confirmed that the conclusion drawn from PCA was reasonable which means that only 3 species can describe the entire fluorescence signal.

\subsection{Numerical simulation of the solvent inter-diffusion}

The precipitation is not observed for a transit time of $100 \mathrm{~ms}$ This is long compared to the time it takes for the THF of the inner flow to diffuse into the outer water flow $(50 \mathrm{~ms})$. In addition monomers are still observed for a transit time of

Table 1 Distribution of each species calculated from the pre-exponential coefficients of the decay model; $\mathrm{M}$ and $\mathrm{E}$ stands for the middle and the edge of the central flow respectively

\begin{tabular}{c|lllll}
\multicolumn{2}{c}{$\begin{array}{c}\text { Transit Place } \\
\text { Time }\end{array}$} & \multicolumn{5}{c}{ Species relative distribution (\%) } \\
\cline { 3 - 6 } & & $\begin{array}{l}\text { Monomer } \\
\left(\tau_{1}=60 \mathrm{ps}\right)\end{array}$ & $\begin{array}{c}\text { Intermediate } \\
\left(\tau_{2}=0.47 \mathrm{~ns}\right)\end{array}$ & $\begin{array}{l}\text { B-phase crystal } \\
\left(\tau_{3}=5.7 \mathrm{~ns}\right)\end{array}$ & $\begin{array}{l}\text { "Nanoparticles" } \\
\left(\tau_{4}=11.4 \mathrm{~ns}\right)\end{array}$ \\
225 & $\mathbf{M}$ & $96.6 \%$ & $2.5 \%$ & $0.9 \%$ & $0 \%$ \\
$\mathrm{mS}$ & $\mathbf{E}$ & $96.2 \%$ & $3.5 \%$ & $0.3 \%$ & $0 \%$ \\
\hline 250 & $\mathbf{M}$ & $80.2 \%$ & $18.0 \%$ & $1.8 \%$ & $0 \%$ \\
$\mathrm{~ms}$ & $\mathbf{E}$ & $74.4 \%$ & $22.2 \%$ & $2.8 \%$ & $0.6 \%$ \\
\hline 275 & $\mathbf{M}$ & $92.5 \%$ & $5.6 \%$ & $1.9 \%$ & $0 \%$ \\
$\mathrm{~ms}$ & $\mathbf{E}$ & $85.0 \%$ & $8.7 \%$ & $4.6 \%$ & $1.7 \%$ \\
\hline 300 & $\mathbf{M}$ & $62.5 \%$ & $21.6 \%$ & $0 \%$ & $15.9 \%$ \\
$\mathrm{~ms}$ & $\mathbf{E}$ & $37.2 \%$ & $29.1 \%$ & $0.4 \%$ & $33.3 \%$ \\
\hline
\end{tabular}

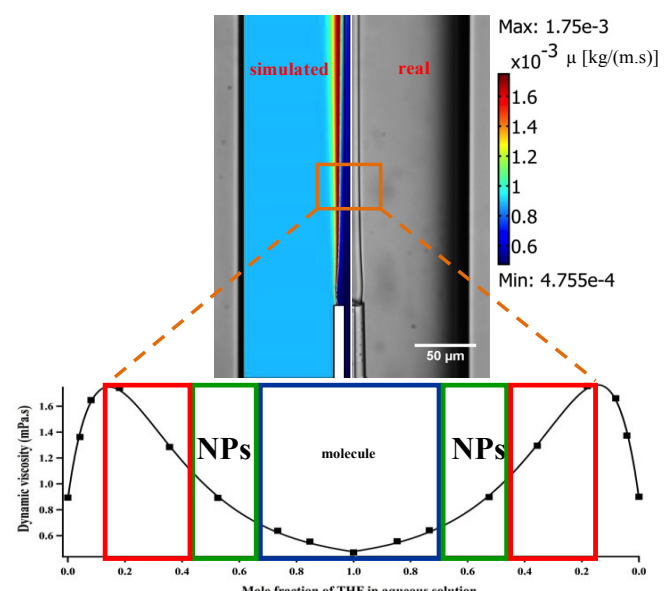

Fig. 6 Calculated dynamic viscosity during the mixing process of THF and water (above) and simplified diagram for the diffusion process and "focusing phenomenon" of the dye (below)

$300 \mathrm{~ms}$. The super-saturation values that are reached after the inter-diffusion of the solvents are high and the aggregation process should be limited by the collision time of the monomers. Similarly, the FLIM images in this study shows that the particles are trapped in the central flow which was also suggested by our earlier study. ${ }^{18}$ Thus, we now come up with a hypothesis of a viscosity barrier existing between two solvents during the mixing. Indeed in Fig. 6, we have shown the simulation calculated by COMSOL Multiphysics (v. 3. 4) (COMSOL AB, Sweden) of the solvent viscosity in the capillary. A raise of viscosity is predicted at the frontier of the two solvents. It is due to the non-linear relationship of the dynamic viscosity with the ratios of THF and water (Fig. 6 below). This might be the reason why the fluorescence signal is confined in the central flow and might be a first indication for a new technique to control the synthesis of nanoparticles.

\section{Conclusions}

A new method to synthesize and observe sub-micrometre particles precipitation was optimized to study and control the early stage of the micro-precipitation process. The developed device is easy to construct and fully compatible with a wide range of solvents. We have used FLIM to detect the oligomers of AIEE molecules that precede the formation of crystals. The PCA analysis of the decays shows that three species are sufficient to describe the data: monomers, oligomers and crystals. PCA was used to calculate the contribution of the three species for each pixel based on their lifetimes. We show that after $300 \mathrm{~ms}$ of residence time, the monomers are still present in the central flow. The presence of a viscous skin at the frontier between THF and water does explain this. Both oligomers and crystals are present at the edge of the flow. The constant ratio between oligomers and crystals shows that nucleation and growth occur simultaneously in our device. 


\section{Acknowledgements}

This work was supported by the cooperation fellowship between ENS Cachan and CentraleSupélec. Tran V. L. acknowledges ENS Cachan International Scholarship for the financial support during his work and would like to thank Pr. Anne Spasojévic de Biré, CentraleSupélec, for helpful discussions. Zuschratter W, Prokazov Y, Turbin E acknowledge BMBF FKZ 13N12675 for financial support.

\section{Notes and references}

1 D. Xia, Y. Gan and F. Cui, Curr. Pharm. Des., 2014, 20, 408-435.

2 I. J. Joye and D. J. McClements, Trends Food Sci. Technol., 2013, 34, 109-123.

3 L. Lu, I. Sevonkaev, A. Kumar and D. V. Goia, Powder Technol., 2014, 261, 87-97.

4 Y. Wang, J. He, C. Liu, W. H. Chong and H. Chen, Angew. Chem. Int. Ed., 2015, 54, 2022-2051.

5 P. Moschou, M. H. J. M. de Croon, J. van der Schaaf and J. C. Schouten, Rev. Chem. Eng., 2014, 30.

6 M. Sultana and K. F. Jensen, Cryst. Growth Des., 2012, 12, 62606266.

7 G. Tresset, C. Marculescu, A. Salonen, M. Ni and C. Iliescu, Anal. Chem., 2013, 85, 5850-5856.

8 V. K. LaMer and R. H. Dinegar, J. Am. Chem. Soc., 1950, 72, 4847-4854.

9 D. Gebauer, M. Kellermeier, J. D. Gale, L. Bergström and H. Cölfen, Chem. Soc. Rev., 2014, 43, 2348.

10 S. Hamad, C. E. Hughes, C. R. A. Catlow and K. D. M. Harris, J. Phys. Chem. B, 2008, 112, 7280-7288.

11 B. Fleury, M.-A. Neouze, J.-M. Guigner, N. Menguy, O. Spalla, T. Gacoin and D. Carriere, ACS Nano, 2014, 8, 2602-2608.

12 S. A. Raina, D. E. Alonzo, G. G. Z. Zhang, Y. Gao and L. S. Taylor, Pharm. Res., 2015, 32, 3660-3673.

13 A. E. S. Van Driessche, G. Sazaki, F. Otálora, F. M. González-Rico, P. Dold, K. Tsukamoto and K. Nakajima, Cryst. Growth Des., 2007, 7, 1980-1987.

14 H.-G. Liao, K. Niu and H. Zheng, Chem. Commun., 2013, 49, 11720.

15 M. Ildefonso, E. Revalor, P. Punniam, J. B. Salmon, N. Candoni and S. Veesler, J. Cryst. Growth, 2012, 342, 9-12.

16 M. Ildefonso, N. Candoni and S. Veesler, Cryst. Growth Des., 2011, 11, 1527-1530.

17 F. Schütze, B. Stempfle, C. Jüngst, D. Wöll, A. Zumbusch and S. Mecking, Chem. Commun., 2012, 48, 2104.

18 S. Desportes, Z. Yatabe, S. Baumlin, V. Génot, J.-P. Lefèvre, H. Ushiki, J. A. Delaire and R. B. Pansu, Chem. Phys. Lett., 2007, 446, 212-216.

19 A. Seth, G. Béalle, E. Santanach-Carreras, A. Abou-Hassan and C. Ménager, Adv. Mater., 2012, 24, 3544-3548.

20 S.-J. Yoon, J. W. Chung, J. Gierschner, K. S. Kim, M.-G. Choi, D. Kim and S. Y. Park, J. Am. Chem. Soc., 2010, 132, 13675-13683.

21 J. Gierschner, L. Lüer, B. Milián-Medina, D. Oelkrug and H.-J. Egelhaaf, J. Phys. Chem. Lett., 2013, 4, 2686-2697.

22 Z. R. Grabowski, K. Rotkiewicz and W. Rettig, Chem. Rev., 2003, 103, 3899-4032.

23 V. Génot, S. Desportes, C. Croushore, J.-P. Lefèvre, R. B. Pansu, J. A. Delaire and P. R. von Rohr, Chem. Eng. J., 2010, 161, 234-239.
24 Y. Liao, V. Génot, R. Méallet-Renault, T. T. Vu, J.-F. Audibert, J.-P. Lemaistre, G. Clavier, P. Retailleau and R. B. Pansu, Phys. Chem. Chem. Phys., 2013, 15, 3186.

25 Y. Prokazov, E. Turbin, A. Weber, R. Hartig and W. Zuschratter, J. Instrum., 2014, 9, C12015-C12015.

26 R. Esposito, C. Altucci and R. Velotta, J. Fluoresc., 2012, 23, 203211.

27 M. A. Digman, V. R. Caiolfa, M. Zamai and E. Gratton, Biophys. J., 2008, 94, L14-16.

28 C. Ruckebusch, M. Sliwa, P. Pernot, A. de Juan and R. Tauler, J. Photochem. Photobiol. C Photochem. Rev., 2012, 13, 1-27. 